Check for updates

Cite this: Chem. Commun., 2021, 57,7252

Received 2nd June 2021, Accepted 18th June 2021

DOI: $10.1039 / \mathrm{d} 1 \mathrm{cc} 02892 \mathrm{~h}$

rsc.li/chemcomm

\section{Direct formation of 4,5-disubstituted carbazoles via regioselective dilithiation $\dagger$}

\author{
Ian A. Pocock, (D) a Alya M. Alotaibi, (DD ${ }^{\text {ab }}$ Kesar Jagdev, (D) ${ }^{a}$ Connor Prior, (D) a \\ Gregory R. Burgess, ${ }^{a}$ Louise Male (D) ${ }^{a}$ and Richard S. Grainger (D)*a
}

\begin{abstract}
Carbazoles are widely exploited for their interesting photophysical and electronic properties, however bay (4,5-) functionalization is challenging, and previously inaccessible through carbazole $\mathrm{C}-\mathrm{H}$ activation. We report a simple methodology which introduces a range of versatile 4,5-functionality, enabling the wider investigation of ring annulation and close proximity effects on carbazole properties.
\end{abstract}

Carbazoles represent a privileged structure within chemistry: their advantageous photophysical and electronic properties have led to multiple applications in organic materials, ${ }^{1}$ sensing, ${ }^{2}$ and as organic photocatalysts. ${ }^{3}$ Carbazoles are also found in a large number of naturally-occurring alkaloids ${ }^{4}$ and other biologically active molecules, ${ }^{5}$ and hence the development of methods for their preparation remains an important area of research. ${ }^{6}$

Groups at the 4- and 5-positions, or bay region, of carbazole are in close proximity, but systematic investigations into such peri-like interactions are limited by the lack of effective preparatory methods and general synthetic building blocks. Thus the relatively few examples of 4,5-disubstituted carbazoles in the literature are prepared from non-carbazole precursors through benzannulation of indoles or pyrroles, ${ }^{6 b}$ or through formation of the central nitrogen heterocycle from biaryls or diarylamines. ${ }^{6 c}$ The influence of close proximity, peri-like interactions on the structure, reactivity and electronic properties of 4,5-disubstituted carbazoles has been noted in a few cases, ${ }^{7,8}$ and carbazoles with additional ring fusion at the 4,5-positions have been investigated in a variety of contexts, but again not synthesized by annulation of carbazole. ${ }^{9}$

Aromatic $\mathrm{C}-\mathrm{H}$ functionalization represents the most direct method for the preparation of substituted carbazoles, however the ease of $C$-substitution is highly positional dependent

\footnotetext{
${ }^{a}$ School of Chemistry, University of Birmingham, Edgbaston, Birmingham B15 2TT, UK. E-mail: r.s.grainger@bham.ac.uk

${ }^{b}$ Prince Sattam bin Abdulaziz University, Saudi Arabia

$\dagger$ Electronic supplementary information (ESI) available: Experimental procedures, analytical data, additional electrophile and substrate screen, X-ray crystallography and copies of NMR spectra. CCDC 2079909-2079912 and 2080733-2080736. For ESI and crystallographic data in CIF or other electronic format see DOI: 10.1039/d1cc02892h
}

(Scheme 1). Functionalization at the 3,6-positions (through electrophilic aromatic substitution ${ }^{10}$ ) and at the 1,8-positions (through directed lithiation ${ }^{11}$ or metal-catalysed $\mathrm{C}-\mathrm{H}$ activation ${ }^{12}$ ) are well established. Other substitution patterns are more difficult to access: 2,7-functionalization is rare, ${ }^{13}$ and there is only one method for $\mathrm{C}-\mathrm{H}$ activation at $\mathrm{C}-4$, through the coupling of $N$-pyrimidinyl carbazoles with tertiary $\alpha$-bromoesters under Ru catalysis. ${ }^{14}$

The combination of $n \mathrm{BuLi}$ and $N, N, N^{\prime}, N^{\prime}$-tetramethylethylenediamine (TMEDA) can be used to regioselectively dilithiate a select range of aromatic systems through directed deprotonation. ${ }^{15}$ Given the known effect of placing a triisopropylsilyl (TIPS) group on an indole nitrogen to block ortho-lithiation, ${ }^{16}$ we hypothesized that the combination of a bulky silyl protecting group on the carbazole nitrogen (to prevent C-1/C-8-lithiation) and the use of $n$ BuLi-TMEDA (to dilithiate at C-4 and C-5) ${ }^{17}$ would offer a simple and convenient approach to 4,5-difunctionalized carbazoles upon electrophilic trapping (Scheme 1). Based on this hypothesis, we herein report the first method for the direct functionalization at both the 4- and 5-positions of carbazole.

$9 H$-Carbazole (1b) and silyl-substituted carbazoles 1a $(\mathrm{R}=\mathrm{TIPS}){ }^{21} \mathbf{1 c}(\mathrm{R}=\mathrm{TES})$ and $1 \mathrm{~d}(\mathrm{R}=\mathrm{TBS})$ were treated with $n \mathrm{BuLi}$ under various conditions, followed by quenching with $\mathrm{D}_{2} \mathrm{O}$, to determine the extent and position of lithiation, and the functional group compatibility of the $N$-silyl group (Table 1).

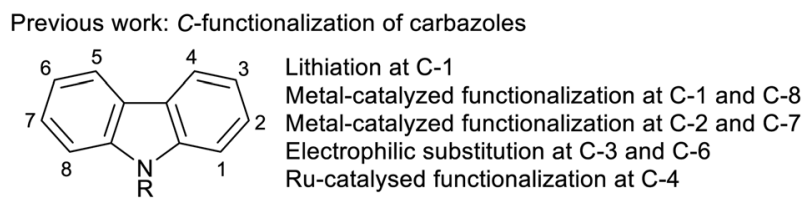

This work: direct functionalization at $\mathrm{C}-4$ and $\mathrm{C}-5$ of carbazole

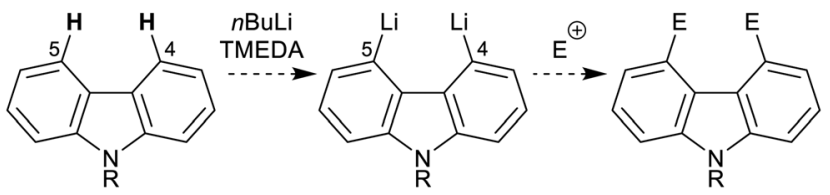

Scheme 1 Considerations in carbazole functionalization. 
Table 1 Deprotonation screen of carbazoles $1 \mathbf{a}-\mathbf{d}$

a R= TIPS; b $\mathrm{R}=\mathrm{H} ; \mathbf{c} \mathrm{R}=\mathrm{TES} ; \mathbf{d} \mathrm{R}=\mathrm{TBS}$

$\%$ deuteration ${ }^{a}$

\begin{tabular}{|c|c|c|c|c|c|c|c|}
\hline Entry & $1(\mathrm{R})$ & Ligand & Time (h) & Temp. $\left({ }^{\circ} \mathrm{C}\right)$ & $\mathrm{C} 1 / 8$ & $\mathrm{C} 2-6$ & C4/5 \\
\hline 1 & $1 \mathbf{a}$ (TIPS) & TMEDA & 3 & 60 & - & - & 70 \\
\hline 2 & 1a (TIPS) & TMEDA & 6 & 60 & - & - & 83 \\
\hline 3 & $1 \mathbf{a}$ (TIPS) & TMEDA & 9 & 60 & - & - & 75 \\
\hline 4 & 1a (TIPS) & TMEDA & 3 & 68 & - & - & 83 \\
\hline 5 & 1a (TIPS) & TMEDA & 6 & 68 & - & - & 79 \\
\hline 6 & $1 b(H)$ & TMEDA & 6 & 60 & 57 & - & 12 \\
\hline 7 & 1c (TES) & TMEDA & 6 & 60 & \multirow{2}{*}{\multicolumn{3}{|c|}{$100 \%$ desilylation }} \\
\hline 8 & 1d (TBS) & TMEDA & 6 & 60 & & & \\
\hline 9 & $1 \mathrm{a}$ (TIPS) & - & 6 & 60 & - & - & - \\
\hline 10 & 1a (TIPS) & PMDTA & 6 & 60 & \multicolumn{3}{|l|}{ Dec } \\
\hline
\end{tabular}

${ }^{a}$ Determined by relative integration of aromatic hydrogen signals in the ${ }^{1} \mathrm{H}$ NMR.

Subjecting $N$-TIPS carbazole 1a to standard $n$ BuLi-TMEDA conditions $^{15 a, c}$ gave $70 \%$ deuterium incorporation at the 4,5positions, as estimated by ${ }^{1} \mathrm{H}$ NMR (Table 1 , entry 1 ), ${ }^{18}$ thus establishing the feasibility of the approach. Extending the reaction time (entries 2 and 3) and increasing the reaction temperature (entries 4 and 5) gave increased levels of deuterium incorporation with the same C-4,5 regioselectivity; however evaporation of hexanes proved troublesome, thus favouring longer reaction times as the more practical conditions (entry 2). A screen of $N$-substituents showed that the free $9 H$-carbazole (1) gave deuteration preferentially at C-1 (entry 6), complementing prior literature in the absence of TMEDA. ${ }^{11 a}$ Smaller $N$-silyl substituents resulted in extensive desilylation (entries 7 and 8). Finally, exploring the role of the ligand, attempting the lithiation in the absence of TMEDA gave no deuterium incorporation (entry 9), while using PMDTA, a known ligand for remote lithiation, ${ }^{19}$ resulted in decomposition of 1a (entry 10).

The conditions from Table 1, entry 2 were screened with a range of different electrophiles to give 4,5-disubstituted $N$-TIPS carbazoles directly from $N$-TIPS carbazole 1a (Fig. 1). Alkylation with iodomethane gave a mixture of starting material, monoand dimethylated products from which the major component, 4,5-dimethylcarbazole 2a, could be separated in 38\% yield. However the larger allyl bromide and benzyl bromide electrophiles failed to react. ${ }^{20}$ Results of trapping with other carbon electrophiles also highlighted the difficulty in incorporating two groups in close proximity in the carbazole bay region. Although reaction with benzophenone was unsuccessful, use of paraformaldehyde gave separable bis-alcohol $3 \mathbf{a}^{21}$ in $43 \%$ yield, along with $23 \%$ of the monoalcohol. Reaction with $\mathrm{CO}_{2}$ gave anhydride $4 \mathbf{a}$ in a pleasing $63 \%$ yield. Trapping with hexafluorobenzene allowed for annulation to the $4 H$-naphtho[1,2,3,4-def]carbazole $5 \mathbf{a}$ in $34 \%$ yield. ${ }^{21}$

Reaction with heteroatom electrophiles was also investigated. Chlorination with $\mathrm{C}_{2} \mathrm{Cl}_{6}$ gave a mixture of monochloride and dichloride, which were separable after removal of the TIPS group from the carbazole nitrogen using TBAF, with dichloride $\mathbf{6} \mathbf{b}^{21}$ isolated in $35 \%$ yield, along with $13 \%$ of the monochloride. Attempted incorporation of larger bromine or iodine were, however, very low yielding, again highlighted the difficulty in incorporating two groups in close proximity in the carbazole bay region. ${ }^{20}$ More successful was where the electrophile was particularly small, or where a ring could be formed in situ, relieving potential peri-like steric and electronic repulsions in the hindered carbazole bay region. Reaction with $\mathrm{B}(\mathrm{OMe})_{3}$ gave boronic anhydride $7 \mathrm{a}$ in $66 \%$ yield after acidic work-up. ${ }^{22}$ Reaction with dimethyldichlorosilane gave silafluorene $8 \mathbf{8}$ in $74 \%$ yield. ${ }^{21}$ Germafluorene 9a was similarly formed in $39 \%$ yield.

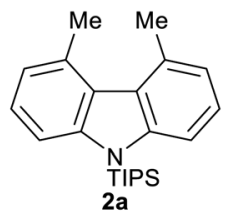

(Mel, 8 equiv.) $38 \%$

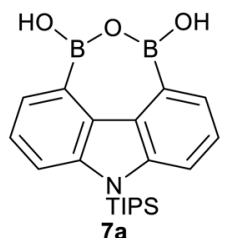

$\left(\mathrm{B}(\mathrm{OMe})_{3}, 20\right.$ equiv.) $66 \%$ a

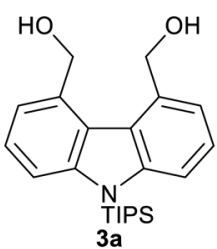

$\left(\left(\mathrm{CH}_{2} \mathrm{O}\right)_{n}, 10\right.$ equiv. $)$ $43 \%$

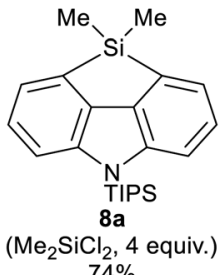

$74 \%$

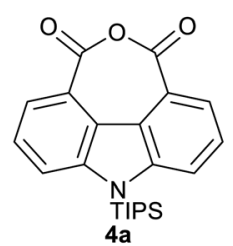

$\left(\mathrm{CO}_{2}\right.$, large excess $)$ $63 \%^{\mathrm{a}}$

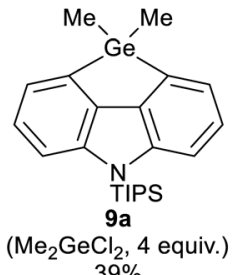

$39 \%$
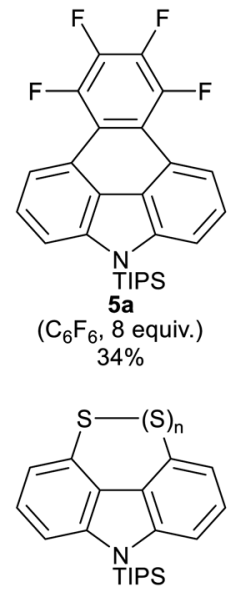

$10 \mathrm{a}(\mathrm{n}=1), 11 \mathrm{a}(\mathrm{n}=2)$

( $\mathrm{S}_{8}, 8$ equiv.) $44 \% 10 a^{c}$
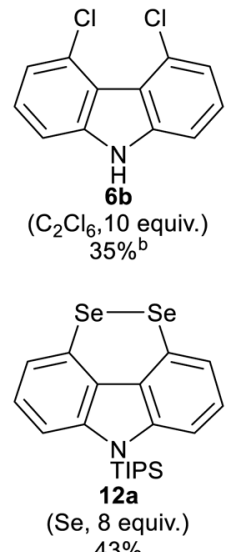

$43 \%$

Fig. 1 4,5-Dilithiation and electrophilic trapping of N-TIPS carbazole 1a. Reaction conditions: (i) $n B$ Bui (4 equiv.), TMEDA (4 equiv.), $60{ }^{\circ} \mathrm{C}, 6$ hours, (ii) $\mathrm{THF},-78{ }^{\circ} \mathrm{C}$ then (electrophile, equiv.). \% yields refer to isolated yields after purification by column chromatography unless otherwise stated. ${ }^{a}$ Isolated yield after purification by trituration with $n$-hexane. ${ }^{b}$ Isolated yield over two steps after removal of TIPS group with TBAF. ${ }^{c}$ Yield of $10 a$ after $\mathrm{NaBH}_{4}$ reduction of mixture of $10 a$ and $11 a$. 
Our interest in peri-substituted naphthalene disulfides and diselenides led us to investigate incorporation of sulfur and selenium at C-4 and C-5. ${ }^{23}$ Reaction with elemental sulfur gave disulfide 10a in $54 \%$ yield on a $3.1 \mathrm{mmol}$ scale. On larger scale (6.2 mmol 1a), mixtures of disulfide 10a and trisulfide 11a were obtained, which could be converged to $10 \mathrm{a}$ in $44 \%$ overall yield by treatment with $\mathrm{NaBH}_{4}$. Reaction with elemental selenium gave diselenide 12a in $43 \%$ yield without evidence of any triselenide formation. X-Ray analyses of disulfide $\mathbf{1 0 b}$ and diselenide $\mathbf{1 2 b}$, obtained after removal of the $N$-TIPS groups with TBAF, are reported in the ESI. $\dagger^{21}$

The functionality embedded in these novel 4,5-disubstituted carbazoles can be further manipulated, increasing the range of carbazoles accessible from this methodology (Scheme 2).

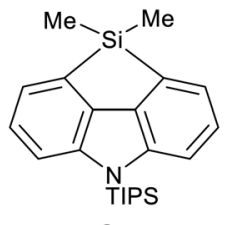

$8 \mathbf{a}$<smiles></smiles>

$8 \mathbf{a}$<smiles>[Z17]n1c2cccc3c2c2c(cccc21)B(O)OB3O</smiles>

$7 a$<smiles></smiles>

$4 a$<smiles></smiles>

$3 a$

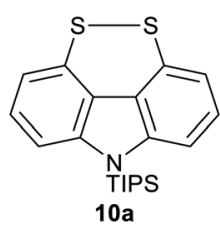

$10 \mathrm{a}$
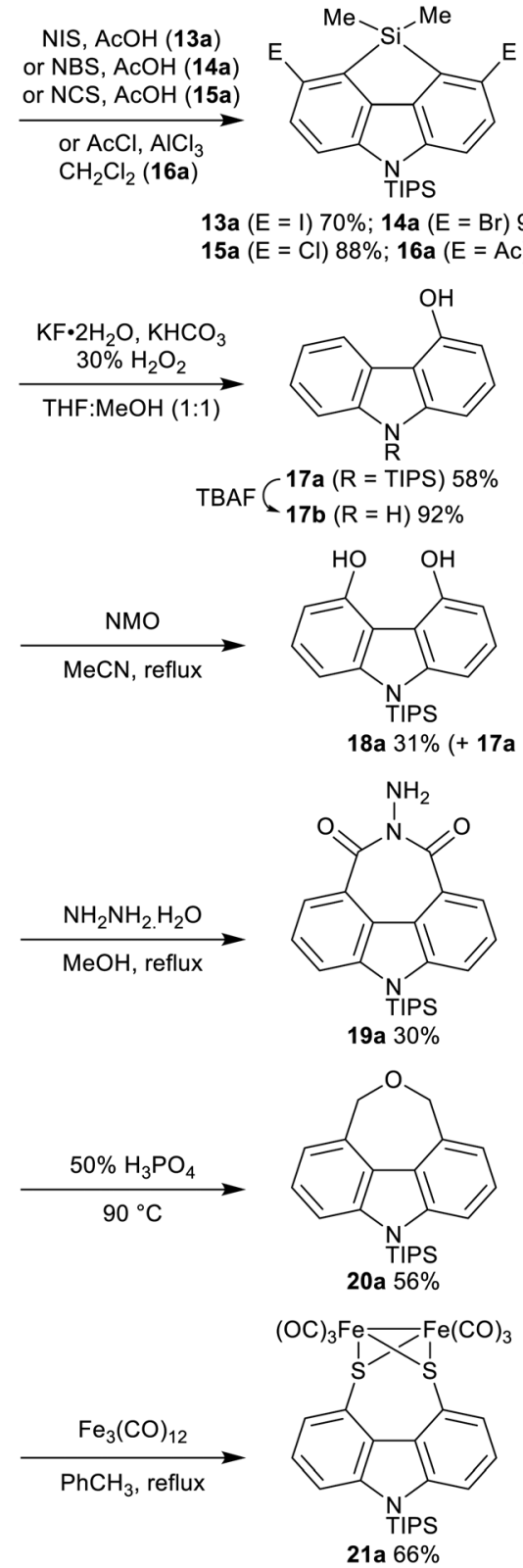

13a $(E=I) 70 \% ; 14 a(E=B r) 91 \%$ 15a $(E=C l) 88 \%$; $16 a(E=A c) 50 \%$

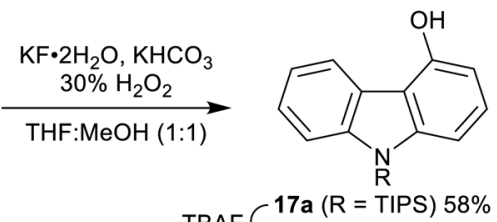

$\operatorname{TBAF}\left(\begin{array}{l}17 \mathbf{a}(\mathrm{R}=\mathrm{TIPS}) 5 \\ 17 \mathrm{~b}(\mathrm{R}=\mathrm{H}) 92 \%\end{array}\right.$

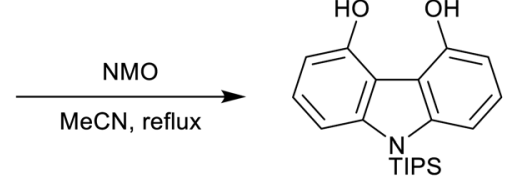

18 a $31 \%(+17$ a $13 \%)$

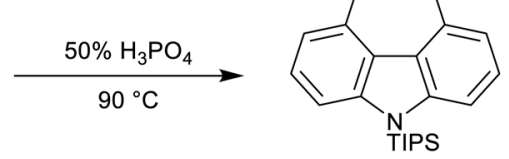

20a $56 \%$

Scheme 2 Selective transformations of 4,5-disubstituted carbazoles.
Regioselective electrophilic aromatic substitution of the fused carbazole-silafluorene $\mathbf{8 a}$ provided the corresponding 3,6disubstituted carbazoles 13a-16a. Silafluorenes have broad application in materials and synthesis, ${ }^{24}$ and the preparation of dihalides 13a-15a in good yields opens up the investigation of these novel heteroatom-bridged heterofluorenes ${ }^{25}$ in further crosscoupling reactions. Oxidation of 8a under Dudley's conditions gave desymmetrized carbazole monoalcohol $17 \mathbf{a}^{26} \mathrm{~N}$-Desilylation of 17a with TBAF gave 4-hydroxycarbazole (17b), a known starting point for natural product syntheses. ${ }^{27}$ Complementary to the mono-oxidation of $\mathbf{8 a}$, the diol 18a was the major product formed in the oxidation of boronic anhydride $7 \mathrm{a}$ using NMO. ${ }^{28}$ The potential of anhydride $4 \mathbf{a}$ was demonstrated through reaction with hydrazine hydrate to give the $N$-iminoimide 19a in $30 \%$ yield (unoptimized). Dehydration of diol 3a to the carbazole-annulated cyclic ether $20 a^{21}$ was achieved using $\mathrm{H}_{3} \mathrm{PO}_{4}{ }^{29}$ Oxidative insertion of $\mathrm{Fe}_{3}(\mathrm{CO})_{12}$ into the disulfide 10a gave the $\mathrm{Fe}_{2}(\mathrm{CO})_{6}$ complex 21a, of interest as a structural mimic of the active site of the enzyme [FeFe] hydrogenase. ${ }^{23 d, 30}$

In conclusion, the first methodology for the direct functionalization of the sterically hindered bay positions of carbazoles is reported, through the simple combination of a bulky TIPS group on the carbazole nitrogen and the use of $n \mathrm{BuLi}$-TMEDA for deprotonation and directed lithiation. With 4,5-substitution being relatively unrepresented in the carbazole literature, and substitution in this bay region effecting, for example, the planarity of the carbazole, ${ }^{8,31}$ this methodology opens up new opportunities for more systematic investigations and future applications in synthesis, catalysis, organic materials and biology.

We thank the Leverhulme Trust (RPG-2017-260), Prince Sattam bin Abdulaziz University, Saudi Arabia, and EPSRC (EP/M508202/1, EP/N509590/1) for funding.

\section{Conflicts of interest}

There are no conflicts to declare.

\section{Notes and references}

1 Recent reviews: (a) D. Devadiga, M. Selvakumar, P. Shetty, M. S. Santosh, R. S. Chandrabose and S. Karazhanov, Int. J. Energy Res., 2021, 45, 6584-6643; (b) F.-M. Xie, J.-X. Zhou, Y.-Q. Li and J.-X. Tang, J. Mater. Chem. C, 2020, 8, 9476-9494; (c) F. Bekkar, F. Bettahar, I. Moreno, R. Meghabar, M. Hamadouche, E. Hernáez, J. L. VilasVilela and L. Ruiz-Rubio, Polymers, 2020, 12, 2227; (d) G. Krucaite and S. Grigalevicius, Synth. Met., 2019, 247, 90-108; (e) M. Steppień, E. Gońka, M. Żyła and N. Sprutta, Chem. Rev., 2017, 117, 3479-3716; $(f)$ B. Wex and B. R. Kaafarani, J. Mater. Chem. C, 2017, 5, 8622-8653.

2 Recent reviews: (a) J. Yin, Y. Ma, G. Li, M. Peng and W. Lin, Coord. Chem. Rev., 2020, 412, 213257; (b) I. Gupta and P. E. Kesavan, Front. Chem., 2019, 7, 841.

3 (a) T. Yabuta, M. Hayashi and R. Matsubara, J. Org. Chem., 2021, 86, 2545-2555; (b) J. Lu, B. Pattengale, Q. Liu, S. Yang, W. Shi, S. Li, J. Huang and J. Zhang, J. Am. Chem. Soc., 2018, 140, 13719-13725; (c) E. Speckmeier, T. G. Fischer and K. Zeitler, J. Am. Chem. Soc., 2018, 140, 15353-15365; (d) J. J. Murphy, D. Bastida, S. Paria, M. Fagnoni and P. Melchiorre, Nature, 2016, 532, 218-222.

4 Reviews: (a) T. Janosik, A. Rannug, U. Rannug, N. Wahlström, J. Slätt and J. Bergman, Chem. Rev., 2018, 118, 9058-9128; (b) A. W. Schmidt, K. R. Reddy and H.-J. Knölker, Chem. Rev., 2012, 112, 3193-3328.

5 Recent reviews: (a) A. Caruso, J. Ceramella, D. Iacopetta, C. Saturnino, M. V. Mauro, R. Bruno, S. Aquaro and M. S. Sinicropi, Molecules, 2019, 
24, 1912; (b) S. Issa, A. Prandina, N. Bedel, P. Rongved, S. Yous, M. L. Borgne and Z. Bouaziz, J. Enzyme Inhib. Med. Chem., 2019, 34, 1321-1346; (c) S. Sellamuthu, G. Gutti, D. Kumar and S. K. Singh, Mini-Rev. Org. Chem., 2018, 15, 498-507.

6 Reviews: (a) S. N. Georgiades and P. G. Nicolaou, Adv. Heterocycl. Chem., 2019, 129, 1-88; (b) A. Banerjee, S. Kundu, A. Bhattacharyya, S. Sahu and M. S. Maji, Org. Chem. Front., 2021, 8, 2710-2771; (c) N. Yoshikai and Y. Wei, Asian J. Org. Chem., 2013, 2, 466-478.

7 Y. Tsunashima and M. Kuroki, J. Heterocycl. Chem., 1981, 18, 715-718.

8 T. Gensch, M. Rönnefahrt, R. Czerwonka, A. Jäger, O. Kataeva, I. Bauer and H.-J. Knölker, Chem. - Eur. J., 2012, 18, 770-776.

9 (a) Z. M. Geng, K. Shibasakia and M. Kijima, Synth. Met., 2016, 213, 57-64; (b) X.-D. Xiong, C.-L. Deng, X.-S. Peng, Q. Miao and H. N. C. Wong, Org. Lett., 2014, 16, 3252-3255; (c) G. Mitchell and C. W. Rees, J. Chem. Soc., Perkin Trans. 1, 1987, 403-412.

10 For a recent example see: X.-T. Wu, E.-K. Xiao, F. Ma, J. Yin, J. Wang, P. Chen and Y.-J. Jiang, J. Org. Chem., 2021, 86, 6734-6743.

11 (a) A. Hallberg and A. R. Martin, J. Heterocycl. Chem., 1984, 21, 837-840; (b) A. R. Katritzky, G. W. Rewcastle and L. M. Vazquez de Miguel, J. Org. Chem., 1988, 53, 794-799.

12 Z.-C. Qi, Q.-X. Lou, Y. Niu and S.-D. Yang, Chem. Commun., 2021, 57, 2021-2024 and references therein.

13 (a) Y. Feng, D. Holte, J. Zoller, S. Umemiya, L. R. Simke and P. S. Baran, J. Am. Chem. Soc., 2015, 137, 10160-10163; (b) G. Yang, P. Lindovska, D. Zhu, J. Kim, P. Wang, R.-Y. Tang, M. Movassaghi and J.-Q. Yu, J. Am. Chem. Soc., 2014, 136, 10807-10813; (c) For direct 1,2-substitution see: D. Wang, M. Li, X. Chen, M. Wang, Y. Liang, Y. Zhao, K. N. Houk and Z. Shi, Angew. Chem., Int. Ed., 2021, 60, 7066-7071.

14 J. A. Leitch, C. J. Heron, J. McKnight, G. Kociok-Köhn, Y. Bhonoah and C. G. Frost, Chem. Commun., 2017, 53, 13039-13042.

15 (a) A. J. Ashe III, J. W. Kampf and P. M. Savla, Heteroat. Chem., 1994, 5, 113-119; (b) X. Li, Y. Zhu, J. Shao, B. Wang, S. Zhang, Y. Shao, X. Jin, X. Yao, R. Fang and X. Shao, Angew. Chem., Int. Ed., 2014, 53, 535-538; (c) V. B. Bonifácio, J. Morgado and U. Scherf, Synlett, 2010, 1333-1336; (d) S. Cossu, G. Delogu, D. Fabbri and P. Maglioli, Org. Prep. Proced. Int., 1991, 23, 455-457; (e) I. A. Kashulin and I. E. Nifant'ev, J. Org. Chem., 2004, 69, 5476-5479.

16 M. Matsuzono, T. Fukuda and M. Iwao, Tetrahedron Lett., 2001, 42, 7621-7623.

17 For rationales of bay-region and peri-dilithiation regioselectivity using $n \mathrm{BuLi}$-TMEDA in related polyaromatics and the potential for bridging dilithiated species, see: $(a)$ W. Bauer, T. Clark and P. V. R. Schleyer, J. Am. Chem. Soc., 1987, 109, 970-977; (b) A. J. Ashe, III, J. W. Kampf and P. M. Savla, J. Org. Chem., 1990, 55, 5558-5559 and references therein.

18 G. Rouquet, D. C. Blakemore and S. V. Ley, Chem. Commun., 2014, 50, 8908-8911.

19 A. B. Bellan and P. Knochel, Angew. Chem., Int. Ed., 2019, 58, 1838-1841 and references therein.

20 Additional electrophiles which were unsuccessful in an initial trapping screen (no reaction or complex mixtures leading to poor yields) are reported in the ESI $\dagger$.

21 CCDC 2079909-2079912 (1a, 8a, 10b and 12b respectively) and CCDC 2080733-2080736 (3a, 5a, 6b and 20a respectively) contain the supplementary crystallographic data for this paper $\dagger$.

22 (a) R. L. Letsinger, J. M. Smith, J. Gilpin and D. B. MacLean, J. Org. Chem., 1965, 30, 807-812; (b) A. Das, A. Hübner, M. Weber, M. Bolte, H.-W. Lerner and M. Wagner, Chem. Commun., 2011, 47, 11339-11341.

23 (a) R. S. Grainger, B. Patel and B. M. Kariuki, Angew. Chem., Int. Ed., 2009, 48, 4832-4835; (b) R. S. Grainger, B. Patel, B. M. Kariuki, L. Male and N. Spencer, J. Am. Chem. Soc., 2011, 133, 5843-5852; (c) B. Patel, J. Carlisle, S. E. Bottle, G. R. Hanson, B. M. Kariuki, L. Male, J. C. McMurtrie, N. Spencer and R. S. Grainger, Org. Biomol. Chem., 2011, 9, 2336-2344; (d) C. Figliola, L. Male, S. L. Horswell and R. S. Grainger, Eur. J. Inorg. Chem., 2015, 3146-3156.

24 (a) For materials applications see: Y. Dong, Y. Takata, Y. Yoshigoe, K. Sekine and Y. Kuninobu, Chem. Commun., 2019, 55, 13303-13306 and references therein; $(b)$ For synthetic applications see: H. Ito, Y. Segawa, K. Murakami and K. Itami, J. Am. Chem. Soc., 2019, 141, 3-10.

25 H. Sasaki, I. Akioka, H. Imoto and K. Naka, Eur. J. Org. Chem., 2021, 1390-1395.

26 J. D. Sunderhaus, H. Lam and G. B. Dudley, Org. Lett., 2003, 5, 4571-4573.

27 C. Brütting, R. Hesse, A. Jäger, O. Kataeva, A. W. Schmidt and H.-J. Knölker, Chem. - Eur. J., 2016, 22, 16897-16911.

28 Y. Chai, M. Zou and M. Zhu, CN107089936, 2017.

29 U. Azzena, S. Demartis, L. Pilo and E. Piras, Tetrahedron, 2000, 56, 8375-8382.

30 For a review see: J. T. Kleinhaus, F. Wittkamp, S. Yadav, D. Siegmund and U.-P. Apfel, Chem. Soc. Rev., 2021, 50, 1668-1784.

31 The C4-C-C-C5 dihedral angle in disulfide $10 \mathrm{~b}\left(11.4(3)^{\circ}, 10.5(3)^{\circ}\right)$ and diselenide $12 \mathbf{b}\left(13.6(4)^{\circ}\right)$ can be compared with the essentially planar carbazole ring system in $\mathbf{1 a}\left(-0.8(5)^{\circ}\right)$. See ref. 21 for crystallography data. 